\title{
Optimization and Simulation of Electrochemical Machining of Cooling Holes on High Temperature Nickel-Based Alloy
}

\author{
Mingxia Chai, Zhiyong Li $^{*}$, Xuening Song, Jianhua Ren, Qingwei Cui \\ School of Mechanical Engineering, Shandong University of Technology, Zi’bo 255049, China \\ *E-mail: 1zy761012@sdut.edu.cn
}

Received: 13 May 2021 / Accepted: 8 July 2021 / Published: 10 August 2021

\begin{abstract}
To improve the electrochemical machining (ECM) precision and machining efficiency of aeroengine turbine blade cooling holes, taking the lateral gap and material removal rate as performance evaluation indicators, the machining accuracy and machining efficiency of ECM cooling holes as a function of the machining voltage, electrode feed rate and electrolyte concentration were explored through orthogonal experiments and single-factor experiments. The results show that among the three process parameters, the electrode feed rate is an important factor affecting the side clearance, and the processing voltage is an important factor affecting the material removal rate, which provides guidance for the optimization of ECM process parameters. Based on the cooling hole samples obtained from basic experiments, the influence of three process parameters on the distribution of the pressure field in the ECM region was analysed by computational fluid dynamics (CFD) simulations. Combined with those in the basic experiments, the optimal process parameters were obtained: machining voltage $U=10 \mathrm{~V}$, electrode feed rate $f=0.66 \mathrm{~mm} / \mathrm{min}$, and electrolyte concentration $\zeta=11 \%$.
\end{abstract}

Keywords: Cooling hole; Electrochemical machining (ECM); Computational fluid dynamics (CFD); Side clearance; Material removal rate

\section{FULL TEXT}

(C) 2021 The Authors. Published by ESG (www.electrochemsci.org). This article is an open access article distributed under the terms and conditions of the Creative Commons Attribution license (http://creativecommons.org/licenses/by/4.0/). 